\title{
Blended Learning as a Means of Foreign Students' Integration into a University Educational Process
}

\author{
https://doi.org/10.3991/ijet.v16i06.19073 \\ Nadezhda Kuzmina ${ }^{(\varpi)}$, Darya Kochkina, Maksim Kuzmin \\ FSAEIHE SUSU (NRU) "South Ural State University \\ (National Research University)", \\ Chelyabinsk, Russian Federation \\ naniku@mail.ru
}

\begin{abstract}
This paper considers the problem of blended learning as a means of foreign students' integration into higher school environment. This process is not that simple, it demands special methods to help foreign students to be integrated easily. The use of blended learning in education facilitates easy students' integration and leads to positive learning results. However, the application of blended learning is connected with challenges both educators and foreign students can face. The aim of the article is to consider and assess the use of blended learning at the lessons of English implemented into a university educational process. For that purpose, we applied such methods as a needs analysis (among lecturers of English from South Ural State University), a questionnaire and an interview (among three groups of students from similar bachelor's programs). The findings show that the majority of those surveyed do understand the importance of blended learning as a means of foreign students' integration, but they are not familiar with the types and how to use them. Based on the results of this analysis, the authors applied blended learning into the process of English teaching, such as flipped classroom, station rotation, and a new online language development course, "Methodological support to the textbook by McCarthy, M. "Touchstone". The drawn conclusions indicate that blended learning allows not only to boost foreign language skills, but to promote easy foreign students' integration into the educational process of the university.
\end{abstract}

Keywords-Blended learning, foreign students' integration, university educational process, language training, learning management system (LMS)

\section{Introduction}

Interstate educational contacts are intensively developing in the modern world, the number of young people who want to get education outside their country is increasing. As it is stated in the "Concept of long-term socio-economic development of the Russian Federation for the period of up to 2020", it is necessary to create conditions for attracting foreign students to Russia [1]. This should be one of the priority tasks in the activities of Russian higher educational institutions so that by 2020 the share of foreign citizens will reach $5 \%$ in the total contingent of university students. According 
to the developers of the concept, the achievement of these planned indicators (targets) will be proof of an increase in the international competitiveness of Russian education and will become a criterion for its high quality, and will also ensure the positioning of Russia as one of the leaders in the export of educational services.

The success of the training of foreign students, their level of professional training largely depends on the integration of foreign students into the socio-cultural life of the host country, and therefore the problem of the integration of foreign students to the conditions of study in higher educational institutions of Russia, which in turn depends on the effective organization of educational interaction.

Currently, issues of adaptation of foreigners to the new environment are considered from the standpoint of philosophy, cultural studies, social psychology, ethnopsychology, and pedagogy. World sociological science began to study the issues of integration and adaptation in the late XIX - early XX centuries. The educational process at a university is always a process of communicative interaction between an educator and students. But not always the possibilities of communication are used in full.

To survive in the realities of a network society and increase competitiveness, leading Russian universities are restructuring their growth strategies in response to the challenges of the fourth industrial revolution. In 2013 the state program was launched to support leading Russian universities (Project 5-100). South Ural State University, being one of 21 participants of this project, determines its main goal as the transformation into a SMART university and prioritizes training of a new generation of leaders capable of facing global challenges of sustainable development and changing the world for the better.

Creating smart educational environment in the university supposes implementing the principles of flexibility in an interactive educational environment (digitalization of education), free access to the content around the world, personalization of teaching, project approach and creation of an integrative scientific and creative space.

In these circumstances, it is necessary to use blended learning that allow different categories of learners to acquire necessary skills autonomously in an interactive form, exchange content, get feedback, and develop educational products. For this purpose, SUSU organizes its own production of modern teaching aids, develops modern forms of distance learning - e-learning and b-learning, as well as mass distance courses in the MOOC format.

However, despite the undoubted advantages of using blended learning in foreign language training at the university, not all participants of the educational process realize the importance and necessity of integrating this innovative tool into teaching and learning processes. The reasons can be very diverse: a negative attitude towards the digitalization of education, low level of computer literacy, the discrepancy between the selected technology and pedagogical goals and tasks, difficulties in solving users' problems, much time and effort to develop, implement and support courses.

The purpose of the research is to provide theoretical substantiation and assessment of blended learning as a means of foreign students' integration into the educational process of the university. To reach that complex aim it's essential, firstly, to gain an insight into bachelors' and educators' understanding of blended learning a foreign language with foreign students, secondly, to find out the reasons for incorporating this 
technology into the process of teaching and studying a foreign language and, thirdly, to examine benefits both for educators and learners from applying this technology in practice.

The subject matter of the study is the process of language training at the nonlinguistic higher school. The scope of the study is blended learning as a means of foreign students' integration into the educational process of the university.

The purpose of the article is to highlight approaches which can show educators how to implement blended learning in English teaching foreign students and reveal advantages and disadvantages while working with this or that form.

The investigation of the research problem is necessary to begin with giving theoretical background and literature review.

\section{Literature Review}

The problem of integrating foreign students into the system of higher education must be considered from a sociological, pedagogical and psychological point of view.

In sociological concepts, the integration process is considered as an active introduction of a person to the value-normative system of a society. M. Weber considered this process through the unity of the individual and his behavior [2]; I. H. Cooley considered the concept of "integration" as the initial unity of the individual and a society; E. Durkheim, along with the concept of "integration" used the concept of "solidarity" as a connecting category between a society and value concepts [3]; J. Habermas understood integration as ensuring the unity of the social world through values and norms [4].

From a psychological point of view, integration is the process by which parts are connected into a whole. Psychological integration serves the organization of complete personal fulfillment, adjusting the individual parts of the individual to each other so as to ultimately obtain a single personality. Integration is an essential step towards individualization and self-fulfillment.

In pedagogy, according to S. N. Babina, "(pedagogical) integration is an educational model of integrative processes occurring in nature and society ... The educational system should create conditions for integrative cognitive activity of students, which contribute to the formation of a holistic worldview in them" [5].

From the point of view of B. G. Zhogin, integration must be viewed as a process and as a result simultaneously, which are characterized by five main components [6]: a sense of belonging, openness, complementarity, support, and alignment.

An analysis of the methodological literature on this topic allows us to conclude that integration is the process of the emergence of new systematic step-by-step features in the learning process in a new unfamiliar educational space.

For emergence of these new systematic features in higher educational space, we should point out the importance of e-learning which is constantly growing. Educational institutions are introducing e-learning because it: 
- Meets the needs of modern students living in the digital world

- Stimulates pedagogical innovations

- Promotes the exchange of knowledge and cooperation at the intra-university and inter-university levels

- Expands the possibilities of distance learning and simplifies access to education for various categories of students

Blended learning is more common in e-learning practice. First of all, it is necessary to analyze the existing approaches to understanding and defining blended learning.

The term "blended learning" has been used in professional literature since the late 90s of the XX century. However, only in 2006 in the book by C. J. Bonk and C. R. Graham "The Handbook of Blended Learning: Global Perspectives, Local Designs", which is still considered one of the most complete and comprehensive studies of blended learning, a general definition was given, which is used by many modern scientists [7].

The authors of the book analyzed the existing interpretations and identified the following as starting points for their analysis. Blended learning is a combination of different learning methods; combination of various teaching methods; combination of training in the course of personal communication with training online [7, p. 39]. The third definition approaches the explanation of blended learning from a historical and technological point of view, as it opposes a conventional form of education using innovative technologies. It is on this opposition that the authors build their own definition. According to Bonk and Graham, “... blended learning is a form of education that combines traditional learning in the course of personal communication (face-toface) with learning through the use of computer technology" [7, p. 42].

Blended learning is interpreted in a different way by Br. Tomlinson and Cl. Whittaker [8]. The authors write that the concept of "blended learning" came from business, where it " was used to describe the process of training / retraining of corporate personnel, and, only then, it began to be applied in matters related to higher education" [8]. Tomlinson and Whittaker argue that the issue is not about the intrinsic characteristics of blended learning, but rather what is being mixed up in modern pedagogical systems. The authors write that almost any system can be considered blended, however, the phenomenon under discussion is characterized precisely by the use of computer technologies in traditional teaching. In addition, in their work, they analyze similar concepts that were proposed by other scientists when describing blended learning: "hybrid or blended learning", "e-learning", "learning using the Internet" [8]. Thus, researchers consider blended learning not as a completely new phenomenon, but rather as a logical, consistent development of traditional forms in a changing environment.

Another interpretation of blended learning is offered by D. Randy Garrison and Norman D. Vaughan [9]. They write: "Blended learning is not just an additional and expensive level of education. It implies a radical change in the classical structure in order to increase student participation and expand access to educational structures on the Internet [9, p. 5]. The authors point out what can lead to fundamental changes: the thoughtful integration of traditional teaching and online learning, rethinking curricula 
to optimize the level of student participation, as well as reducing the number of traditional classes.

I. A. Malinina, based on the experience of using technologies of blended learning in a foreign language in higher education, defines blended learning as "... a combination of "live" learning with learning using Internet resources, primarily of the second generation, allowing for joint activities of participants in the educational process. Learning is recognized as blended if from 30 to $79 \%$ of the study time is spent online" [10]. At the same time, the author believes that blended learning can be considered either as part of distance learning, or as its evolution. However, a key element is the presence of face-to-face interaction between teachers and students.

A. V. Loginova defines the considered form of training as "a method that combines traditional face-to-face training and some elements of distance learning" [11].

Based on the above analysis of various interpretations, we propose to consider blended learning as a means of training organization, within which the traditional form is blended with distance learning, which implies the use of computer technologies and Internet resources to maximize the effectiveness of both forms of education.

As blended learning has a key element of face-to-face interaction between teachers and students, it will promote foreign students' integration into a university educational process, thus encouraging emergence of new systematic step-by-step features in the learning process in a new unfamiliar educational space.

Based on the results of theoretical analysis, we consider applying blended learning into the process of English teaching, such as flipped classroom, stations rotation, and a new online language development course, "Methodological support to the textbook by McCarthy, M. "Touchstone" which was specially designed and implemented through the Moodle.

\section{$3 \quad$ Methodology}

There were three different strands to our research and analysis; firstly, a study of methodologies, secondly the findings from questionnaires distributed to bachelors and interviews with them, finally a needs analysis among educators-lecturers of English from South Ural State University, which focused on their experience in blended learning.

The recipients were to indicate their institute or high school at the university, sex, and age and then to answer six questions in the questionnaire:

1. What types of blended learning for a foreign language do you know?

2. What types of blended learning do you use more often at the university?

3. What is blended learning used for?

4. How often do you use blended learning for learning a foreign language?

5. Do you think that bachelors should learn basics of blended learning not only in their native language but in English as well?

6. Does blended learning help you integrate into a university educational process? How? 
Bachelors were also interviewed. Educators-lecturers of English from South Ural State University answered two questions in the interview:

1. What types of blended learning would you like to learn how to use in English?

2. What challenges do you face in using blended learning in English?

\subsection{Role of the questionnaire and the interview methods}

The method of a questionnaire is quite popular. It's anonymous, letting the participants feel free when answering the questions. Closed and open-ended questions provide information that can be easily converted into quantitative (e.g., count "yes" or "no") and qualitative (e.g., analysis of words used to express opinions) data.

One of the disadvantages of questionnaires is that they may not be informative in the analysis of emotions or feelings. Secondly, they lack details, because the space for writing answers is limited. However, interviews allow researchers to get more information about the subject matter; respondents' answers are more spontaneous and reflect their thinking.

In our questionnaire, we got data on how familiar bachelors are with different types of blended learning. The interview highlighted bachelors' level of competence in using blended learning in English.

\subsection{Respondents}

The participants of the questionnaire were students from similar bachelor's program at South Ural State University (national research university), Chelyabinsk, Russia. The experiment was carried out in September 2019. Bachelors from the similar program were asked if they would participate in this study by completing the questionnaire and answering the questions of the interview.

Almost all students agreed to participate, and a total of 60 completed questionnaires were obtained and interviews taken. Among 60 respondents, 33 or $55 \%$ were female while 27 or $45 \%$ were male. This inequality is explained by the fact that more female respondents agreed to participate in the experiment.

According to the respondents' institute or high school, the distribution is the following: 36 or $60 \%$ are from School of Electronic Engineering and Computer Science, 24 or $40 \%$ are from Institute of Engineering and Technology.

Generally, 30 students which are $50 \%$ are between $18-20$ years of age, followed by the rest or the other 50\% who are between 20-22 years of age. This can be explained by the fact that mostly second year students were interviewed, some of them entered the university after college, which brings the age difference.

Mostly foreign students were from Tadzhikistan (42\%), Kazakhstan (33\%), Uzbekistan (16\%) and Kyrgyzstan (9\%).

40 educators (lecturers of English) were interviewed to gain data if the educators of SUSU are ready to implement blended learning or not, what problems they have in using blended learning in English in the educational process of the university. 


\section{$4 \quad$ Results}

The research purpose was to gain bachelors' understanding of blended learning a foreign language and if it helps foreign students integrate into a university educational process. The results are presented in the form of an answer analysis and the data were interpreted in percentage terms, from the point of view of the most frequently used answers.

\subsection{What types of blended learning for a foreign language do you know?}

We asked students about the types of blended learning they know which they can use for learning a foreign language. The majority of respondents gave not so many answers. Our analysis in Fig. 1 shows that remote blended learning, flex blended learning and individual rotation blended learning are most frequently mentioned types in students' answer sheets.

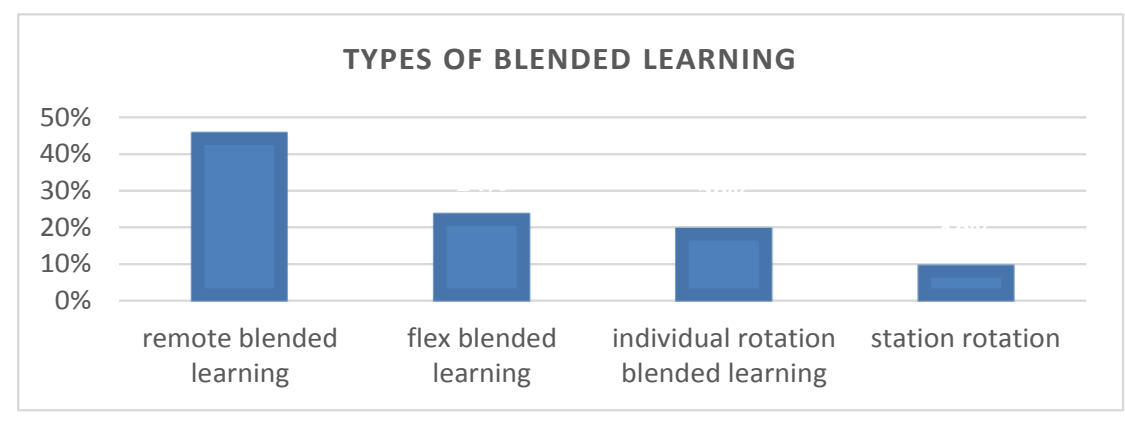

Fig. 1. Types of blended learning students mentioned by frequency

\subsection{What types of blended learning do you use more often at the university?}

Students were also asked what types of blended learning they use more often at the university. The results are shown below in Table 1. The first two positions by frequency in Table 1 completely coincide with data in Fig. 1. But still we should point out that students are not acquainted with many types of blended learning, it means that educators do not use them at their lessons. $28 \%$ of students do not use any blended learning at the university.

Table 1. Frequency of blended learning that students use at the university

\begin{tabular}{|l|c|}
\hline \multicolumn{1}{|c|}{ Type of blended learning } & Frequency \\
\hline Remote blended learning & $48 \%$ \\
\hline Flex blended learning & $24 \%$ \\
\hline No use & $28 \%$ \\
\hline
\end{tabular}




\subsection{What is blended learning used for?}

We analysed all the answers in terms of core notions.

- For better and easy learning of a language $-32 \%$

- For motivating students - $26 \%$

- For better integration of any students into educational process $-18 \%$

- For uncovering students' creativity - $14 \%$

- For turning students from passive ones to active participants of the educational process at the university $-10 \%$

\subsection{How often do you use blended learning for learning a foreign language?}

Students were asked to estimate how often they use blended learning for learning a foreign language. $64 \%$ of respondents use different remote online sites quite often on their own not at the lessons, and 36\% less often. Fifty-two respondents mentioned that blended learning is a great means of integrating and motivating them to learn a foreign language concerning their communication with foreigners. Those who use blended learning very rarely admitted that they use social networks for educational purposes.

\subsection{Do you think that bachelors should learn basics of blended learning not} only in their native language but in English as well?

All the respondents answered yes in response to this question. The follow-up questions were asked in the interview after the questionnaire had been completed. The interview proved the answers gained in the questionnaire.

\subsection{Does blended learning help you integrate into a university educational process? How?}

In response to this question all the respondents answered yes. Blended learning provides self-control of the path, time, place and pace of learning for a student, as well as the integration of the learning experience with the teacher and online. It promotes extensive use of the organization of group learning activities, including joint work on projects, discussions, seminars organized in the form of electronic conferences, forums, synchronous and asynchronous in time. In the context of blended learning, group work is becoming much more - it stimulates the development of online communication skills. All these points promote foreign students' integration into a university educational process.

Educators (lecturers of English) from South Ural State University answered two questions in the interview. 
4.7 What types of blended learning would you like to learn how to use in English?

Educators were asked to give answers what types of blended learning they would like to learn how to use in English. The suggestions by respondents are shown in Fig. 2. Almost a half of respondents needed to study all the types. There appear to be differences in the responses to questions about blended learning in native and foreign languages. The answer "Flex BL" was not given. "Flipped classroom", "Station rotation" and "Remote BL" are regarded by educators as the most necessary in mastering blended learning.

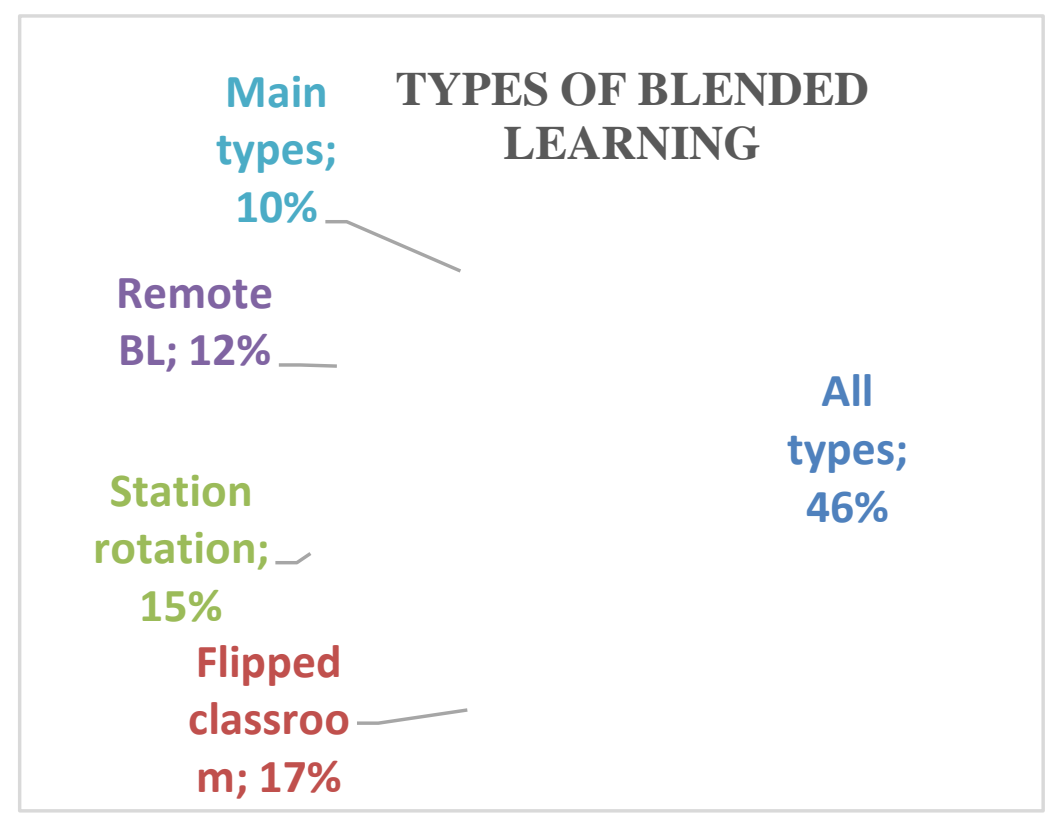

Fig. 2. Educators' needs analysis

\subsection{What challenges do you face in using blended learning in English?}

We analyzed all the answers in terms of core notions.

- Educators are afraid of not being able to cope with technical difficulties - 35\%

- Mastering blended learning are time-consuming - 25\%

- Educators do not know how to organize their lesson using blended learning - 25\%

- Educators are ready to cope with all the difficulties and implement blended learning at their lessons - $15 \%$ 


\section{Discussion}

The results surely point out that blended learning should be widely applied as a means of integration both in learning and teaching foreign languages. Integration of a variety of blended learning types helps to change the language training process way and encourage foreign students' integration into an educational process in general. Having analyzed the results of the needs analysis, the questionnaire and the interview, there have been actively applied and integrated some blended learning types. Precisely there has been specially designed a new online language development course, "Methodological support to the textbook by McCarthy, M. "Touchstone" which was implemented through the Moodle (the university corporate learning management system); we also applied such blended learning types as flipped classroom and station rotation.

\subsection{The online language development course "Methodological support to the textbook by McCarthy, M. "Touchstone"}

The educators were asked to suggest blended learning types that they would like to learn how to use in English, and they mentioned flipped classroom, remote blended learning etc. which are possible with the help of the university corporate learning management system Moodle. That is why there has been designed a new online foreign language development course "Methodological support to the textbook by McCarthy, M. "Touchstone".

The online course was made for university students of nonlinguistic majors. The main goals of this course are to increase the effectiveness of foreign language learning by providing students with lots of additional materials for studying and working out basic language skills and to promote easy foreign students' integration into the educational process of the university.

The course contains 12 units and 5 interconnected modules in each unit such as Grammar, Vocabulary, Time to Read, Time to Write and More to Explore (additional material). All these modules are aimed at integrated development of language skills; encouraging independent activity and better integration of students into educational process; they apply an individual and needs-oriented approach. The course has a simple structure and interface that makes it user-friendly even for those who are not techsavvy and of low language level.

The structure of each unit is the same throughout the course. Each unit starts with the Grammar and Vocabulary module which consists of interactive exercises for different kinds of grammar points and vocabulary, games and quizzes. All grammar exercises are accompanied by colorful and informative pictures which help students understand and do the tasks correctly. This module starts with an information block (Language Summary). The Language Summary presents the core vocabulary of the corresponding unit and helps to increase the knowledge of high-frequency words and phrases. The examples are given in Table 2. 
Table 2. Units and vocabulary topics

\begin{tabular}{|l|l|}
\hline \multicolumn{1}{|c|}{ Unit } & \multicolumn{1}{c|}{ Vocabulary } \\
\hline Relationships & Circle of friends \\
\hline What if? & Wishes / dilemmas \\
\hline Tech savvy? & How things work \\
\hline Impressions & Speculating \\
\hline
\end{tabular}

Interactive lexical exercises for differentiation and identification of lexical units, exercises for the development of word-building and contextual guesses, exercises for equivalent replacements, etc. allows to revise and reactivate the lexical minimum of the unit, encourage students to use new vocabulary, use proper vocabulary in the context of specific communicative situations. The vocabulary module is also interconnected with the Grammar one.

All grammar topics are accompanied by related vocabulary to make students able to express themselves on proper lexical and grammar levels and recycle the vocabulary of the unit when doing grammar exercises. The examples are given in Table 3.

Table 3. Grammar topics and the corresponding vocabulary ones

\begin{tabular}{|l|l|}
\hline \multicolumn{1}{|c|}{ Grammar topics } & \multicolumn{1}{c|}{ Vocabulary } \\
\hline Relative clauses & Circle of friends \\
\hline Phrasal verbs & Dating \\
\hline If clauses & Wishes \\
\hline Present Perfect & Movies \\
\hline
\end{tabular}

Grammar module lets students revise the theoretical material presented in the form of tables and charts. Students are provided with all grammar structures in the form of clear and memorable student-friendly reference material. They are supposed to answer questions on theory and do a set of interactive grammar exercises, thus foreign students are provided with thought-provoking and motivating practice. The module recycles such grammar points as Reported Speech, Present, Past and Future Tenses, the Passive, Infinitives and Gerunds, Quantifiers, etc.

The Reading module satisfies the needs of helping to build vocabulary and consolidate grammar. It is called Time to Read. The texts are selected in accordance with the system of international examinations, so this is the first step towards the international language examinations preparation [12]. The reading module contains engaging and motivating texts, followed by challenging tasks which are aimed to help students to read better, e.g., guess the contextual meaning of words and phrases.

The writing module, Time to Write, provides the students with clear, detailed instructions before they do a guided writing task themselves. It is impossible to imagine the modern society without the communication via the Internet, social networks and a variety of mobile applications [13,14]. Young people are writing and communicating in English more than ever. These writing tasks review vocabulary and grammar of the unit and are focused on punctuation, spelling, connectors and many other writing skills. The students are supposed to describe themselves, write an informal letter and a formal e-mail, describe a building, give their opinion, etc. 
More to Explore module presents additional tasks which help students broaden their horizon, understand high-frequency phrases in common situations, e.g., checking in at the airport, at a department store or at a pharmacy, etc.

This new online foreign language development course "Methodological support to the textbook by McCarthy, M. "Touchstone" gives all opportunities to educators to have more time for the speech practice at their lessons. Foreign students are supposed to get acquainted with all the necessary information at any time convenient to them and may prepare questions beforehand [15]. All these contribute to an easy integration into an educational process.

\subsection{Flipped classroom (via LMS Moodle)}

Our analysis shows that flipped classroom model of education is the most frequently used form of blended learning. A flipped classroom (lesson) is a teaching model in which the educator provides material for independent study at home, and in the faceto-face lesson the material is reinforced. We used vodcasts, podcasts, and prevodcasting. Before getting into the details, let's understand the key concepts.

A podcast is an audio file (audio lecture) that its creator subscribes via the Internet. Recipients can download podcasts to their devices, both landline and mobile, or listen to lectures online. Vodcast (i.e., video on demand) is about the same as podcast, only with video files. Pre-vodcasting is an educational method in which an educator creates a vodcast with his/her lecture so that students get an idea of a topic even before the lesson in which this topic will be discussed. Pre-vodcasting method is the original name of a flipped class method.

There is a technology for using vodcasts in the educational process using special software:

- CMS (Content Management System) - used to create and manage the content of educational materials

- LMS (Learning Management System, distance learning system) - provides access to educational materials, organizing feedback and horizontal links, etc. We used the university corporate learning management system Moodle

The Flipped Class is a learning model in which doing homework, among other things, includes the use of vodcast technologies:

- Watching a video (ex. "How to make friends")

- Reading educational texts (ex. "What makes a good friend"), considering explanatory pictures (ex. Grammar reference: Present Simple)

- Passing tests for the initial assimilation of the topic (ex. Vocabulary activity and reading tests)

Class work is devoted to the analysis of the complex theoretical part and questions that students have in the process of doing homework (no more than $25-30 \%$ of the time). Also in the classroom, students under the supervision of an educator solve practical problems and carry out research tasks. After the lesson in the classroom at 
home, practical tasks are completed, tests are performed to understand and consolidate the topic covered. The transition to the flipped classroom model is a transition from teacher leadership to student leadership. This transition is figuratively described as a change in the role of an educator from "sage on the stage" to "guide on the side" $[16,17,18]$.

Foreign students cooperate and communicate with fellow-students better solving practical problems and carrying out research tasks.

\subsection{Station rotation}

The results of the educators' interview show that station rotation is evaluated as vital in mastering blended learning.

In the station rotation model, a class is divided into groups, and these groups are transferred between different stations. Some of the students start the lesson under the guidance of an educator, while the rest work in groups or study online. Then the groups move to other stations so that during the lesson they visit each of them. For example, a group that worked with an educator moves to a project activity station where they work on team projects. The last station for this group is an online learning station, where students study with computers or work with tablets. The composition of the groups from class-to-class changes depending on the pedagogical task.

There can be two stations - a workstation with an educator and an online workstation. In this case, it is recommended to conduct project work classes or classes in an interactive form at least every third or fourth class. An option with four stations is also possible - a station for working with an educator, an online work station, a station for working on a team project, a station for individual independent work.

The goal of the educator work station is to provide each student with effective feedback. Feedback from the educator has the maximum impact on the quality of education, therefore, improving the quality of feedback and increasing the time of educator-student contact have a positive effect on academic performance. At the station for work with an educator, the educator has the opportunity to take into account the characteristics of the group of students, especially foreign ones, with whom he/she works, as well as their individual characteristics by dividing into groups and reducing the number of students in the group. For example, if you are working with a group of laggards, you might want to focus more on a topic they didn't understand, give each student feedback on that topic, and suggest an individual work plan for the problematic material.

The purpose of the online work station is to give each student the opportunity to develop independent work skills, personal responsibility, develop self-regulation and learn to learn. At the online work station, students can learn new material, test their knowledge and practice skills. The number of resources in our online language development course "Methodological support to the textbook by McCarthy, M. "Touchstone" are abundant and sufficiently varied to provide students with the opportunity to become deeply familiar with the topic. The student gets access to the materials of not only one lesson, but the whole topic in order to enable everyone to go at their own pace, what is more important for foreign students to integrate $[19,20]$. 
The purpose of the project activity station is to provide an opportunity to apply knowledge and skills in new, practical situations, develop communicative competencies and receive feedback from groupmates. Studies show that feedback from other students is one of the factors influencing the growth of students' subject knowledge. In addition, in high school the focus shifts from the teacher to the peers. Therefore, project work and feedback become the main drivers of student development. Students are invited to split into groups of 2-3-4 people, depending on the assignment, some tasks can be performed by the whole group (7-10 people). At the project activity station different forms of application of knowledge and skills are possible:

- Board games on the topic under study

- Group practice-oriented tasks

- Mini-competitions

- Small studies

- Quest, etc.

\section{Conclusion}

The research paper has revealed that the majority of students understand the importance of blended learning as a means of foreign students' integration into the educational process of the university, but they are not familiar with the types and how to use them. It leads to the conclusion that educators practically do not implement any blended learning types at their lessons. The results of the study also show that educators have low level of blended learning awareness. Applying these types is usually stopped by technical difficulties and lack of time for mastering them.

However, foreign students and educators are optimistic about mastering and implementing of blended learning types into the process of language training. The faceto-face classes approach to foreign languages teaching must be supported by modern and up-to-date blended learning technologies as they are mutually supportive and lead to higher academic results. Universities should modernize their policies on the wide integration of blended learning types so that students, especially foreign ones, could succeed in their studying. Every student has his/her own learning style, needs and requirements, blended learning helps to provide resources and tools to satisfy this diversity, make the integration process easy and learning environment more fascinating.

Appropriate application and choice of blended learning types can eliminate the blocking factors and make these technologies effective. Proper integration of blended learning into classroom activities and foreign students' individual work will definitely not only promote learning opportunities and the development of language skills, but will facilitate easy foreign students' integration into a university educational process. 


\section{$7 \quad$ Acknowledgement}

The work was supported by Act 211 of the Government of the Russian Federation, contract №02.A03.21.0011.

\section{$8 \quad$ References}

[1] Strategy 2020: The new growth model - a new social policy. [Online]. Available: http://2020strategy.ru/documents/32710234.html

[2] Doeckel, B. (2002). Das Versachlichungs konzept im Werk Max Webers. - Hamburg University Press

[3] Durkheim, E. (2008). Sociology: its subject, method, purpose. - Moscow, Terra-Knizhniy club, pp. 48

[4] Rahm, C. (2005). Recht und Demokratie bei Jürgen Habermas und Ronald Dworkin. Frankfurt am Main: Lang. cop., pp. 36

[5] Babina, S.N. (2010). Preparing future teachers of physics and technology for the integration of technological and physical education of students. - Moscow, Pedagogy, pp. 56

[6] Zhogin, B.G., Maslova, T.F., Shapovalov, V.K. (2008). Integration of forced migrants into the local community: experience of practical and research activities. - Stavropol, Stavropol service school, pp. 47

[7] Bonk, Curtis J., Graham, Charles R. (2006). The Handbook of Blended Learning: Global Perspectives, Local Designs, Pfeiffer, pp. 39, 42

[8] Tomlinson, B., Whittaker, C. (2013). Blended Learning in English Language Teaching: Course Design and Implementation [Online]. British Council, p. 258 Available: http://www.teachingenglish.org.uk/sites/teacheng/files/D057_Blended\%20learning FINAL WEB\%20ONLY v2.pdf

[9] Garrison, D., Vaughan, N. (2008). Blended learning in higher education: Framework, principles, and guidelines, Jossey-Bass, p. 272

[10] Malinina, I.A. (2013). Application of technologies of blended learning of a foreign language in higher education // Modern scientific research and innovations, No. 10. [Online]. Available: http://web.snauka.ru/issues/2013/10/27936

[11] Loginova, A.V. (2015). Blended learning: advantages, limitations and concerns [Online]. Young scientist, No. 7. Available: http://www.moluch.ru/archive/87/16877/

[12] Guo, Lan et al. (2017). Design and Implementation of English Reading Examination System Based on WEB Platform. International Journal of Emerging Technologies in Learning (iJET), [S.1.], v. 12, n. 12, pp. 45-56. https://doi.org/10.3991/ijet.v12i12.7959

[13] Shi, Shaohua. (2016). Computer English Teaching Model Based on Multimedia Platform. International Journal of Emerging Technologies in Learning (iJET), [S.1.], v. 11, n. 08, p. pp. 59-64. https://doi.org/10.3991/ijet.v11i08.6050

[14] Kuzmina, N., Kochkina, D. (2017). Implementation of the model of forming the future managers' readiness for business correspondence in the educational process of the university, ICERI2017 Proceedings, 10th annual International Conference of Education, Research and Innovation, 16th - 18th of November, pp. 2658-2662. https://doi.org/10.21125/ iceri.2017.0758

[15] Kochkina, D., Kuzmina, N. (2017). Innovative technologies employment as a support in the process of foreign languages teaching, ICERI2017 Proceedings, 10th annual International Conference of Education, Research and Innovation, 16th - 18th of November, pp 2653-2657. https://doi.org/10.21125/iceri.2017.0757 
[16] Yu, Yanan; Qi, Aili. (2018). Teaching System of Smart Learning Environment for Aerobics Course. International Journal of Emerging Technologies in Learning (iJET), [S.1.], v. 13, n. 05, pp. 165-176, https://doi.org/10.3991/ijet.v13i05.8440

[17] Kuang-wu, L. English teachers' barriers to the use of the computer-assisted language learning. [Online]. Available: http://iteslj.org/Articles/Lee-CALLbarriers.html

[18] Andrade, M. Role of technology in supporting English language learners in Today's Classrooms. [Online]. Available: https://tspace.library.utoronto.ca/bitstream/1807/66995/1/And rade_MariadeLourdes_201406_MT_MTRP.pdf

[19] Mason, R., Rennie, F. (2007). Using Web 2.0 for learning in the community. The Internet and Higher Education, 10, 196-203. https://doi.org/10.1016/j.iheduc.2007.06.003

[20] Durocher, K. The importance of balancing classroom technology use. [Online]. Available: http://gettingsmart.com/2016/12/technology-productively-in-the-classroom/

\section{Authors}

Nadezhda Kuzmina is an associate professor of the Foreign Languages Department at South Ural State University, Chelyabinsk, Russian Federation.

Darya Kochkina is a senior lecturer of the Foreign Languages Department at South Ural State University, Chelyabinsk, Russian Federation.

Maksim Kuzmin is a senior lecturer of the Financial Technologies Department at South Ural State University, Chelyabinsk, Russian Federation.

Article submitted 2020-10-06. Resubmitted 2020-11-17. Final acceptance 2020-11-18. Final version published as submitted by the authors. 